\title{
Spatial Firing Correlates of Physiologically Distinct Cell Types of the Rat Dentate Gyrus
}

\author{
Joshua P. Neunuebel ${ }^{1,3}$ and James J. Knierim ${ }^{1,2,3}$ \\ ${ }^{1}$ Krieger Mind/Brain Institute, Johns Hopkins University, Baltimore, Maryland, $21218{ }^{2}$ Solomon H. Snyder Department of Neuroscience, Johns Hopkins \\ University School of Medicine, Baltimore, Maryland 21205, and ${ }^{3}$ Department of Neurobiology and Anatomy, University of Texas Medical School at \\ Houston, Houston, Texas, 77030
}

The dentate gyrus (DG) occupies a key position in information flow through the hippocampus. Its principal cell, the granule cell, has spatially selective place fields. However, the behavioral correlates of cells located in the hilus of the rat dentate gyrus are unknown. We report here that cells below the granule layer show spatially selective firing that consists of multiple subfields. Other cells recorded from the DG had single place fields. Compared with cells with multiple fields, cells with single fields fired at lower rates during sleep were less bursty, and were more likely to be recorded simultaneously with large populations of neurons that were active during sleep and silent during behavior. We propose that cells with single fields are likely to be mature granule cells that use sparse encoding to potentially disambiguate input patterns. Furthermore, we hypothesize that cells with multiple fields might be cells of the hilus or newborn granule cells. These data are the first demonstration, based on physiological criteria, that single- and multiple-field cells constitute at least two distinct cell classes in the DG. Because of the heterogeneity of firing correlates and cell types in the DG, understanding which cell types correspond to which firing patterns, and how these correlates change with behavioral state and between different environments, are critical questions for testing long-standing computational theories that the DG performs a pattern separation function using a very sparse coding strategy.

\section{Introduction}

The dentate gyrus (DG) is the first stage in the classic "trisynaptic loop" model of hippocampal circuitry (Ramon y Cajal, 1995; Amaral and Witter, 1989). Granule cell activity drives the population of CA3 neurons, DG mossy cells, and local DG interneurons via powerful mossy terminal synapses or en passant synapses (McNaughton and Morris, 1987; McNaughton and Nadel, 1990; Acsády et al., 1998). DG neurons have spatially selective firing fields (O'Keefe, 1976; Jung and McNaughton, 1993), and altering the activity of the DG disrupts spatial learning tasks (Sutherland et al., 1983; Whishaw, 1987; McNaughton et al., 1989; Xavier et al., 1999; McHugh et al., 2007; Hunsaker and Kesner, 2008; Hunsaker et al., 2008). Most theories of DG mnemonic function propose that this region uses a sparse encoding mechanism to subserve pattern separation, in which similar input patterns from the entorhinal cortex are distributed across the large granule cell population to decorrelate the patterns to reduce the probability of retrieval errors (McNaughton and Morris, 1987; O'Reilly and

\footnotetext{
Received Dec. 5, 2011; revised Jan. 19, 2012; accepted Feb. 1, 2012.

Author contributions: J.P.N. and J.J.K. designed research; J.P.N. performed research; J.P.N. analyzed data; J.P.N. and J.J.K. wrote the paper.

This work was supported by National Institutes of Health Grants R01 NS39456 and T32 NS07467. We thank Dr. Sachin Deshmukh and Dr. Francesco Savelli for discussions pertaining to the data analysis, Jeremy Johnson for assistance in spike sorting, and Dr. Matthew Shapiro for valuable comments on this manuscript.

Correspondence should be addressed to James J. Knierim, Johns Hopkins University, Krieger Mind/Brain Institute, 338 Krieger Hall, 3400 North Charles Street, Baltimore, MD 21218. E-mail: jknierim@jhu.edu.

J.P. Neunuebel's present address: Janelia Farm Research Campus, Howard Hughes Medical Institute, 19700 Helix Drive, Ashburn, VA 20147.

DOI:10.1523/JNEUROSCI.6038-11.2012

Copyright $\odot 2012$ the authors $\quad 0270-6474 / 12 / 323848-11 \$ 15.00 / 0$
}

McClelland, 1994; Rolls and Kesner, 2006; Rolls, 2007; Myers and Scharfman, 2009). Intriguingly, DG granule cells are one of the few neurons in the mammalian brain in which neurogenesis occurs throughout the adult lifespan (Altman and Das, 1965; Kaplan and Hinds, 1977; Kuhn et al., 1996).

Prior studies reported that some DG cells fired in multiple locations in an environment, whereas other cells fired in single locations, similar to CA1 and CA3 place cells (Jung and McNaughton, 1993; Leutgeb et al., 2007). These studies argued that both types of firing patterns were likely to be from granule cells, because the recording sites were near the granule layer and granule cells significantly outnumber the other cell types of the DG. However, histological identification of recording location may be insufficient to positively identify cell types in the DG. Large mossy cells of the hilus can be recorded from electrodes located $300 \mu \mathrm{m}$ away from each other (i.e., larger than the width of the granule layer), and newborn granule cells tend to reside at the interface between the granule cell layer and hilus before migrating primarily into the lower two-thirds of the layer (Kempermann et al., 2003). Thus, it is difficult to distinguish whether one is recording mature granule cells, newborn granule cells, or cells of the hilus based solely on histology. Whether DG cells with different spatial firing patterns (i.e., single or multiple fields) derive from the same cell type or different cell types is an important question, as other parameters of these cell types may have important implications for functional theories (e.g., pattern separation and sparse encoding).

In the present study, we recorded the activity of neurons histologically localized to the DG during both sleep and behavioral 
foraging. Using primarily physiological criteria, we demonstrate that putative excitatory neurons of the DG separate into two classes of cells. We propose that putative mature granule cells form a very sparse code and tend to fire in single locations, whereas cells with multiple firing fields may correspond to cells of the hilus or to adult-born granule cells.

\section{Materials and Methods}

Subjects and surgery. Seven male, Long-Evans rats, between 5 and 6 months old, were purchased from Charles River Laboratories and individually housed on a $12 \mathrm{~h}$ light/dark cycle with ad libitum access to water. Under aseptic conditions, rats were implanted with a custom-designed recording drive containing 20 independently movable tetrodes. All surgeries and animal procedures complied with National Institutes of Health guidelines and were approved by the Institutional Animal Care and Use Committees at Johns Hopkins University and the University of Texas Health Science Center at Houston. In all animals, 5 tetrodes targeted the CA3 region and 13 tetrodes targeted the DG. To optimize the proportion of tetrodes entering the DG and CA3, recordings were performed during surgery to identify the location of the lateral edge of CA3, which served as a landmark for the medial/lateral placement of the drives (range 3.2 to $4.9 \mathrm{~mm}$ lateral to bregma). For the anterior/posterior placement of the drive, the most lateral tetrode was placed $3.2-4.4 \mathrm{~mm}$ posterior to bregma.

Training and recording. Approximately 2 weeks before surgery, rats were habituated daily to human contact ( $30 \mathrm{~min})$ and trained to sleep in a small dish located on a pedestal $(30 \mathrm{~min})$. After recovering from surgery (5-7 d), rats were placed on a food-restricted diet to reduce their body weight to $80-90 \%$ of the free-feeding weight. During initial training sessions, chocolate sprinkles were dispersed throughout a cardboard box $(63.5 \mathrm{~L} \times 66 \mathrm{~W} \times 59.7 \mathrm{H} \mathrm{cm})$ and rats gradually learned to forage for the reward. The reward was eventually reduced to a few sprinkles periodically tossed into the chamber. After the rats acclimated several days to foraging and the environment, the surroundings were switched to a larger box $(135 \mathrm{~L} \times 135 \mathrm{~W} \times 30 \mathrm{H} \mathrm{cm})$ with white wooden walls located in the room that housed the recording equipment. Training continued in this environment until units were detected and experiments were initiated. Briefly, a series of experiments was conducted over 9-14 d, which involved rats foraging in an open environment or circumnavigating a track. Before and following the experiment each day, extensive periods of sleep and quiet rest were recorded (30-60 min each period) as the rats lay in a small holding dish $(25 \mathrm{~cm}$ diameter $)$ with paper towel bedding. Results from the sleep data and the first session that rats foraged in an open-field environment each day (larger box, $135 \mathrm{~L} \times 135 \mathrm{~W} \times 30 \mathrm{H} \mathrm{cm}$ or small box, $58 \mathrm{~L} \times 58 \mathrm{~W} \times 30 \mathrm{H}$ ) were examined and included in this report; the data recorded as rats ran on a circular track were not essential for the conclusions of the current study and will be presented in a future report.

Electrophysiological recordings. A Cheetah Data Acquisition System (Neuralynx) simultaneously acquired up to 72 channels (18 tetrodes) of single-unit data and continuously recorded local EEG activity from 21 channels. Neural signals were recorded with fine microwire electrodes (12 $\mu \mathrm{m}$ nichrome or $17 \mu \mathrm{m}$ platinum-iridium), were amplified (10005000 gain), and were filtered between $600 \mathrm{~Hz}$ and $6 \mathrm{kHz}$ to optimize recording neural spikes or between 1 and $300 \mathrm{~Hz}$ for local field potentials (LFPs). Units and LFPs were sampled at 32 and $1 \mathrm{kHz}$, respectively. The headstage contained a circular array of red and blue light-emitting diodes (LEDs) over the head and a $13 \mathrm{~cm}$ extension that contained green LEDs behind the head to track the rat's position and head direction.

Tetrode advancement occurred over $\sim 3$ weeks, during which each tetrode was independently lowered in small increments on a daily basis. The advancement of tetrodes was assessed by examining the changing patterns in LFP activity in conjunction with units appearing and disappearing. After entering the CA1 layer, tetrodes were advanced at a similar rate for an additional $300 \mu \mathrm{m}$ until gamma activity and dentate spikes in the LFP were detected (Bragin et al., 1995a,b). The presence of these signals denoted that tetrodes were approaching the dentate granule layer and the tetrodes were then lowered $\sim 10-20 \mu \mathrm{m}$ per day until units were observed during long periods of sleep and quiet rest in the holding dish. After detecting units during sleep, recordings were performed as the animal circumnavigated a track and foraged in an open field. If the tetrode detected units that fired during behavior (either session), the tetrode was no longer adjusted. All tetrodes that did not detect cells that were active during behavior were advanced by $10 \mu \mathrm{m}$. This continued until at least five cells were detected that fired during behavior. Once the tetrodes were putatively located in the proper positions, the advancement of most tetrodes was permanently stopped. However, if all units were lost on a tetrode, it was slightly adjusted (typically $<20 \mu \mathrm{m}$ ) and allowed to stabilize for $12 \mathrm{~h}$ before the start of the next experiment. For rats 227 and 232, tetrodes that did not detect cells during the experiment were advanced by $10 \mu \mathrm{m}$ each day after the recording session.

Unit isolation. Single units were manually isolated off-line, using custom-written software, based on multiple waveform characteristics (i.e., spike amplitude, area under the waveform, and valley depth, which is the lowest point of the waveform following the peak of the action potential) detected concurrently on the four slightly different recording locations of the tetrode. The unit isolation procedure was performed with the user blinded to the histological localization of the tetrodes. The isolation quality of each cell was rated 1 (very good) to 5 (poor) depending on the cluster's separation from background noise and other clusters. Cluster isolation judgments were made completely independent of any of the behavioral firing correlates of the cells. All cells rated as marginal or poor isolation (categories 4 and 5) were excluded from all analyses. Cells that fired $<75$ spikes and had a spatial information score that was $<0.5$ bits/spike and/or was statistically insignificant $(p>0.01)$ were considered inactive during foraging behavior. The spatial information score was calculated using the same algorithm used in Skaggs et al. (1996). Statistical significance was calculated by a shuffling procedure in which the spike train of the cell and the position record of the rat were shuffled relative to each other by a random amount, a firing rate map was created from the shuffled data, and the spatial information was calculated from the shuffled rate map. This procedure was repeated 100 times for each cell, and the cell's measured information score was considered significant at the $p<0.01$ level if all of the information scores from the shuffled data were less than the score from the unshuffled data (Skaggs et al., 1996).

Data analysis. Firing rate maps were constructed by dividing the number of times a cell fired in each pixel of a $64 \times 48$ grid by the total time the rat occupied the pixel. Each square pixel was $\sim 2.64 \mathrm{~cm}^{2}$ (small box) and $\sim 3.38 \mathrm{~cm}^{2}$ (large box). The rate map was smoothed using an adaptive binning algorithm as described by Skaggs et al. (1996). To calculate the number of fields for each cell, all pixels in the rate map with a mean firing rate that exceeded $20 \%$ of the cell's peak firing rate were identified. A subfield was then defined as a region with a minimum of 10 contiguous pixels that each met the $20 \%$ of peak firing rate criterion. The mean in-field firing rate was ascertained by averaging the mean firing rate of each pixel in the field.

Sleep was defined as a period of time that neural activity was recorded while rats were in the small holding dish on a pedestal before or following behavior on the circular track or square enclosure. The quality of sleep was variable from one rat to the next and one session to the next. Usually, rats lay motionless in the dish with their eyes closed during the sleep session. At times, rats would wake from sleep and then stretch or groom. Other times, rats moved around the small dish. We made no attempt to measure sleep states; the main point was to allow plenty of time to accumulate spikes from potentially present low-rate cells during periods in which the rat was mostly inactive.

To exclude analysis of repeated samples of the same cells across days, we separately analyzed recordings from a tetrode with active cells only on (1) the day that the most sleep clusters were detected on that tetrode and (2) the first day that an active cell was detected on that tetrode. Analyses reported in the results are based on recordings from the day with the most sleep clusters (1); however, results based on the first day that an active cell was detected (2) showed similar trends. All statistical analyses were performed in MATLAB.

Histological procedures. After completing the last experiment, lesions ( $10 \mu \mathrm{A}$ for $10 \mathrm{~s}$ ) were made on a subset of tetrodes to aid in track identification (i.e., to help distinguish one tetrode from another). Tetrode 

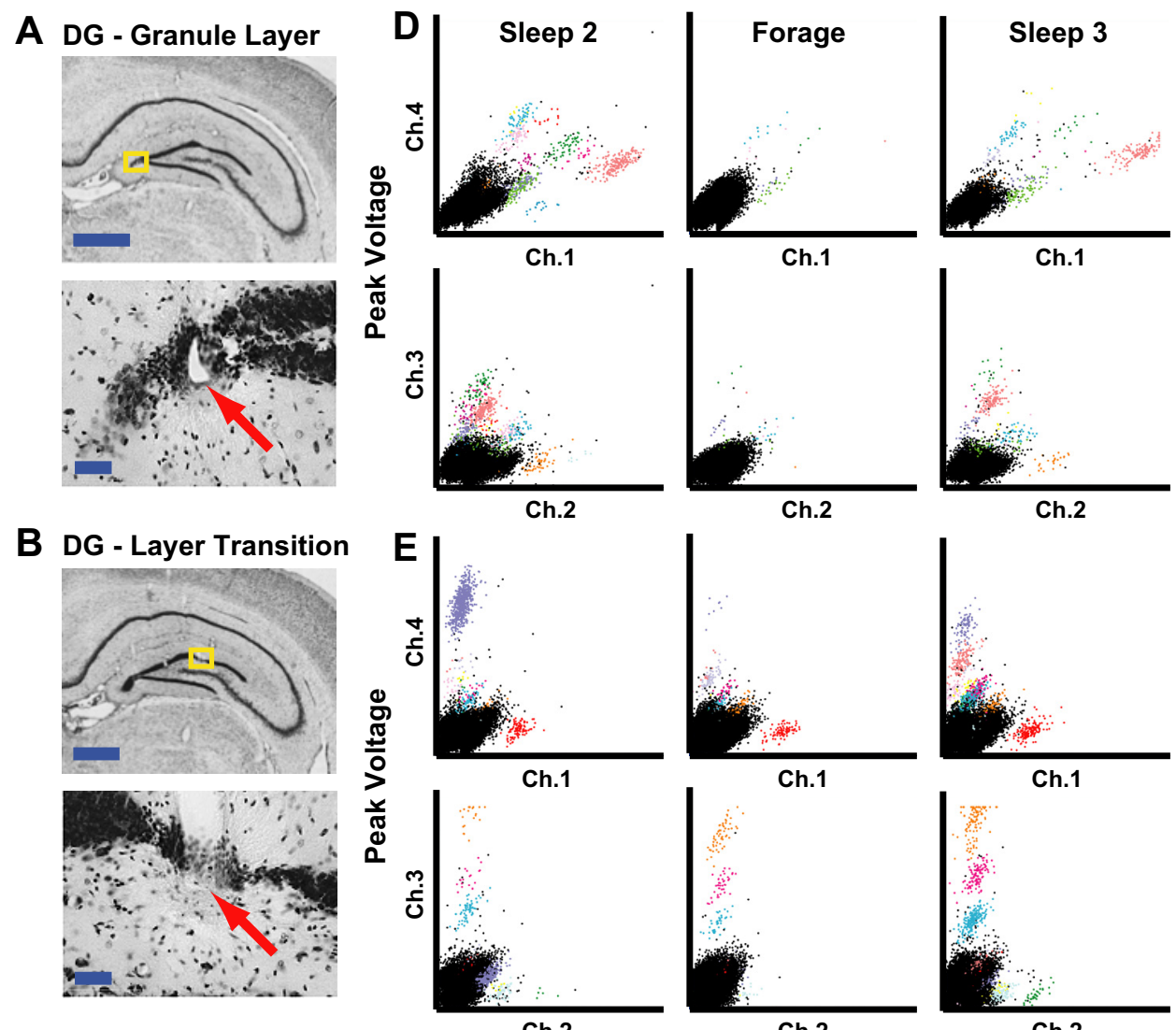

\section{DG - Below Granule Layer}
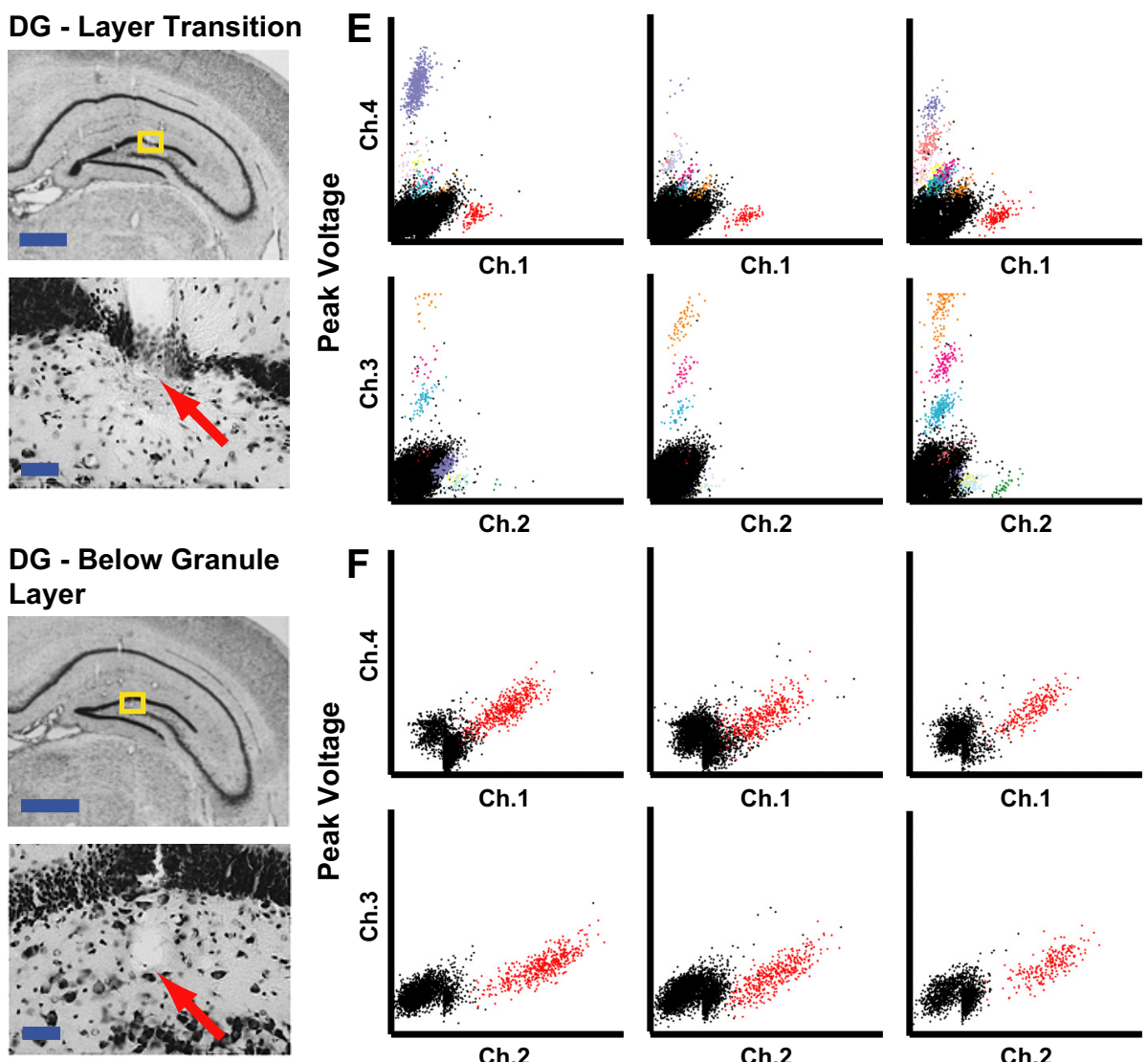

Ch.2
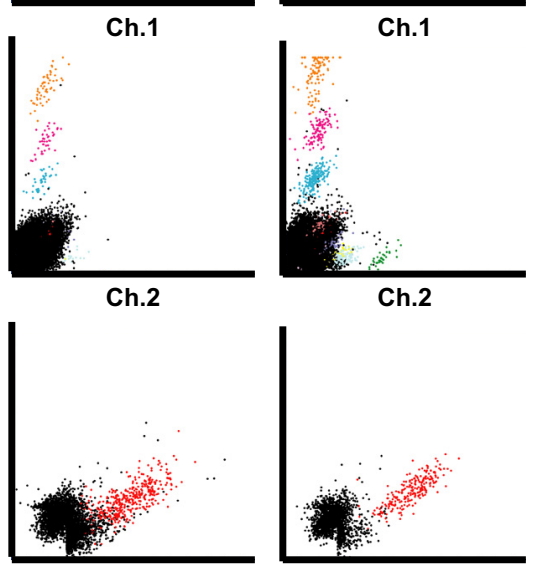

Ch.1

Ch.1
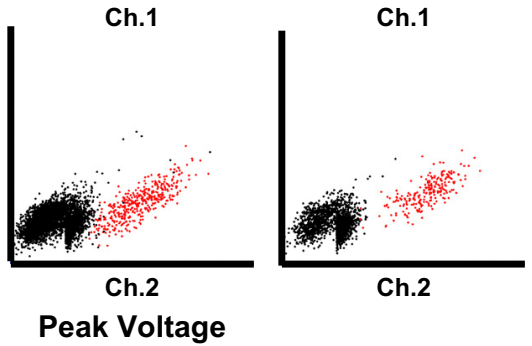

Peak Voltage

Figure 1. Examples of $D G$ recordings. $A-C$, Histology from rat 153 showing tetrodes targeting the $D G$ subfield of the hippocampus localized to the granule cell layer $(A)$, a region near the transition between the granule cell layer and hilus $(\boldsymbol{B})$, and below the granule cell layer $(\boldsymbol{C})$. The regions of interest (yellow boxes) are magnified to show the tips of the tracks (arrows). Scale bars: $1 \mathrm{~mm}$ (top) and $50 \mu \mathrm{m}$ (bottom). $\boldsymbol{D}-\boldsymbol{F}$, Scatter plots showing the maximum height of triggered action potentials on two channels of a tetrode during two sleep sessions and a foraging session that each lasted $30 \mathrm{~min}$. The data plotted in $\boldsymbol{D}-\boldsymbol{F}$ were recorded on the tetrodes shown in $\boldsymbol{A}-\boldsymbol{C}$, respectively. To show the peak voltage on every channel for all spikes, two pairwise comparisons were plotted (top, channel 1 vs 4; bottom, channel 2 vs 3). Each cluster of colored points was considered well isolated (see Materials and Methods).

tips were visible even in tracks without lesions. Rats were killed the following day by injection of Euthasol followed by transcardial perfusion with formalin. Coronal slices $(40 \mu \mathrm{m})$ were cut from the brain on a freezing microtome, mounted, stained with cresyl violet, and photographed. Electrode tracks and the tetrode that generated them were identified and assigned to an anatomical layer depending on the region where the track stopped.

\section{Results}

Recordings of the DG were obtained from seven rats implanted with independently movable multitetrode arrays as they quietly lay on a pedestal before and following a foraging session in an open field. Prior reports stated that many granule cells are virtually silent when the rat is immobile, but awake, and that they begin to fire sparsely when the rat starts sleeping (Jung and McNaughton, 1993; Skaggs et al., 1996). Our anecdotal observations in pilot studies confirmed these reports: in simultaneous recordings of CA1 and DG, we often observed high levels of CA1 unit activity when the animal was in the large irregular activity (LIA) state of the LFP during quiet wakefulness, with virtually silent DG unit activity, such that it was not obvious that the DG electrodes 

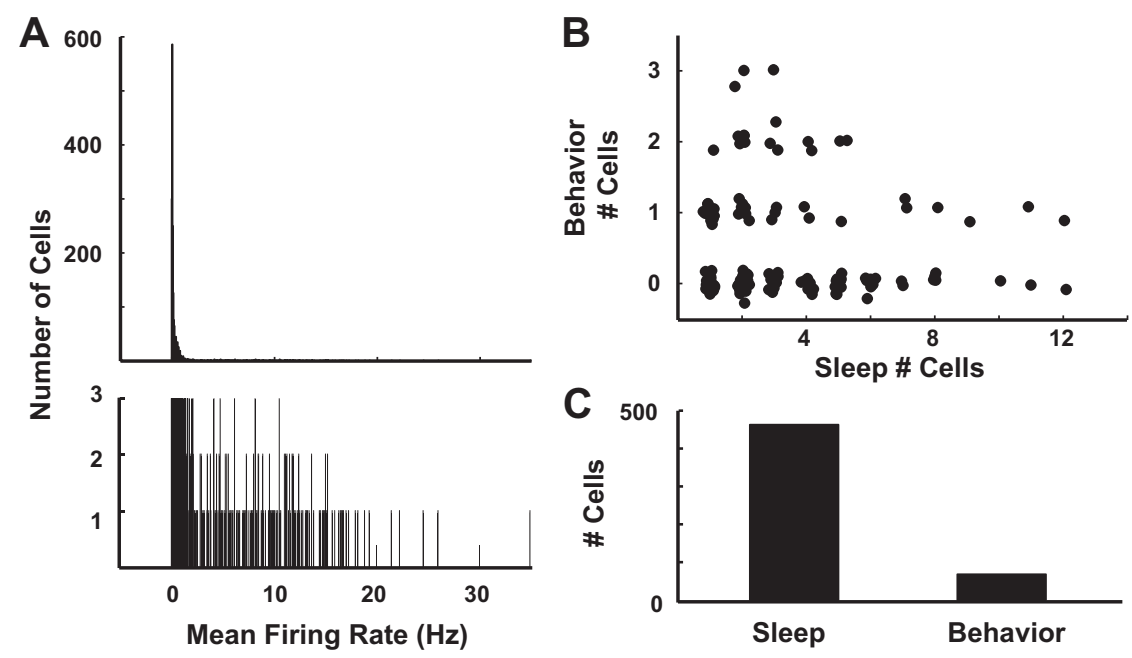

Figure 2. Proportions of DG cells that fire during sleep and behavior suggest two populations of neurons. A, Histogram of the mean firing rates during sleep for all cells detected on tetrodes localized to the $D G$ of seven rats (top). The bottom graph magnifies the bins showing the cell counts ranging from 1 to 3 to visualize the range of firing rate bins $(0.05-35 \mathrm{~Hz})$. $\boldsymbol{B}$, Scatter plot of the number of cells active during behavior versus the number of cells detected during sleep. To aid in visualization of the overlapping data points, jitter was added to the points. C, Summary of data in B showing the number of cells firing during sleep and behavior.

were in a cell layer at all. When the animal closed its eyes and fell asleep, however, units began to fire on the previously silent DG electrodes. Thus, in the present study, after observing the gamma activity and dentate spikes, the neural activity observed on the tetrodes was monitored during sleep for at least $30 \mathrm{~min}$ to determine whether cells were present. Experimental recordings started when at least 5 cells showed place fields as the rats ran on one of the behavioral apparatus used (see Materials and Methods), and the tetrodes were not moved thereafter for the remaining 4-14 d of recordings before the animals were killed (except for minor adjustments on a small number of tetrodes; see Materials and Methods). Over the course of the recording days, the animals experienced a number of different tasks; on some days this included foraging for food in an open field. The present report concerns only the open-field sessions.

Tetrodes localized to the DG were partitioned into three groups based on the location of where the track ended relative to the granule cell layer (tracks that extended into the CA3c pyramidal layer were excluded from analysis). Figure $1 A$ shows a representative electrode track localized to a region at the crest joining the dorsal and ventral blades of the DG. High magnification indicated that the tip of the tetrode was in the granule cell layer near the boundary between the granule cell and molecular layers. Figure $1 B$ shows a representative track in the transition zone between the hilus and the granule cell layer. Figure $1 C$ shows a representative track localized near the boundary between the hilus and zone 3 of Amaral (Amaral, 1978), approximately midway between the granule cell layer and the CA3c pyramidal layer. Figure $1 D$ shows the waveform peak cluster plots for one recording day from the tetrode in Figure $1 A$. After two initial sleep sessions (Sleep $1=1 \mathrm{~h}$; home cage $=2 \mathrm{~h}$ without recording; Sleep $2=30 \mathrm{~min}$ ), rats ran a $\sim 20 \mathrm{~min}$ foraging session in the open field. Following the open-field session, a third sleep session was recorded (Sleep $3=30 \mathrm{~min}$ ). This tetrode displayed multiple clusters during Sleep 2 and Sleep 3 with very sparse firing during the foraging behavior. The most active cell during the $\sim 20 \mathrm{~min}$ foraging session fired only 20 spikes $(0.016 \mathrm{~Hz})$. Similarly, Figure $1 E$ shows that the track ending at the transition between the granule layer and hilus (Fig. $1 B$ ) recorded spikes from multiple clusters during both sleep sessions, with most of the clusters firing relatively sparsely during the foraging behavior (the most active cell was the red cluster on channel 1, which fired only 85 spikes in the $\sim 28 \mathrm{~min}$ recording session, for a firing rate of 0.05 $\mathrm{Hz}$ ). Figure $1 \mathrm{~F}$ shows one recording day from the tetrode in Figure $1 C$. In both sleep sessions and the foraging session, only one well isolated cluster was active, and it was active in all three sessions. The cell fired 399 spikes during the $\sim 27 \mathrm{~min}$ foraging session $(0.24 \mathrm{~Hz})$. These three examples show that the number of cells recorded simultaneously on a tetrode may vary depending on the location of the electrode tip and on the animal's behavioral state.

To quantify differences in the proportion of active cells between sleep and behavior across all tetrodes, we first excluded putative inhibitory interneurons from the study. We plotted the cells according to their mean firing rate during sleep (Fig. 2A) and verified that the majority (61\%) of cells fired at very low rates $(<0.15 \mathrm{~Hz})$ and a small minority $(9 \%)$ fired $>2$ Hz. Similar to prior reports (Jung and McNaughton, 1993; Shen et al., 1998; Gothard et al., 2001; Leutgeb et al., 2007), we restricted our analysis to the low-rate, putative excitatory cells that fired $<2 \mathrm{~Hz}$. Figure $2 \mathrm{~B}$ plots the number of clusters on each of 41 tetrodes during the preforage sleep period against the number of active cells recorded during the foraging session; 23 foraging sessions contributed to this plot. Active cells during behavior were defined as those cells having a statistically significant $(p \leq 0.01$; see Materials and Methods) spatial information score that exceeded 0.5 bits/spike and fired $>75$ spikes during the session. Active cells during sleep were defined as those firing four or more spikes with a firing rate $<2 \mathrm{~Hz}$ (cells firing $>2 \mathrm{~Hz}$ were presumed to be interneurons). Only 5 of the 7 rats were used in this analysis, as two rats performed poorly in the open-field task and did not adequately sample the environment. Because the same tetrodes contributed multiple data points to this plot over days, with presumed overlap of the recorded cells, statistical tests were not conducted on this particular plot (see further analyses for statistical validation of the results). Nonetheless, inspection of the plot reveals a number of patterns. First, all 23 tetrodes that detected six or more clusters during sleep had at most one active cell during behavior; 6 tetrodes had one active cell, whereas the remaining 17 tetrodes had no active cells during behavior. Second, tetrodes that detected five or fewer sleep clusters had as many as three active cells during behavior. There were three examples of a tetrode detecting more cells during behavior than sleep; in these cases, the cells were presumably silent during sleep, as inspection of the clusters before and after sleep showed that the recordings were stable. Figure $2 C$ summarizes the data in Figure $2 B$ and shows that 68 cells $(15 \%)$ were active during behavior compared with 463 cells recorded during sleep.

Figure $2 B$ shows a negative relationship between sleep clusters and behavior clusters. If these data came from a single, homogeneous population, one would predict a positive relationship between the number of sleep clusters and the number of behavior clusters (i.e., a greater number of cells recorded during sleep should produce a proportionately greater number 
A

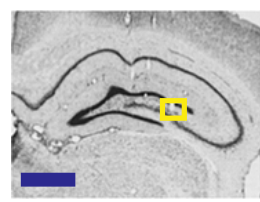

B

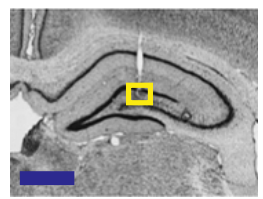

C

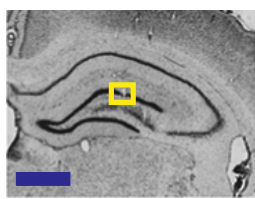

D

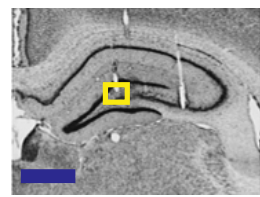

$\mathrm{E}$

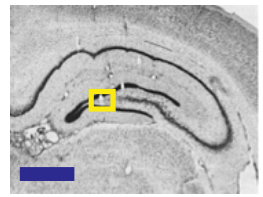

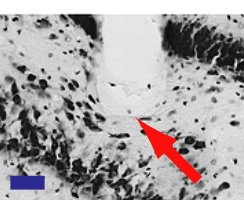
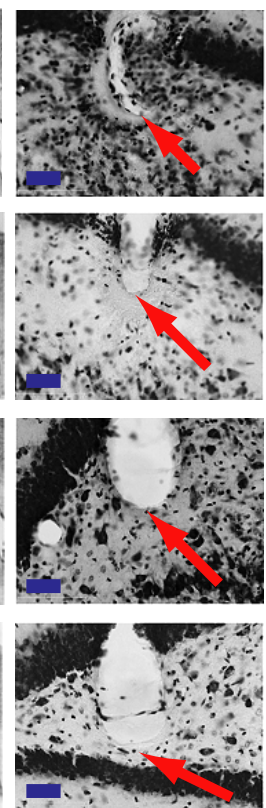

153-04 Sc17 Cell1
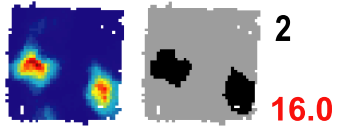

197-14 Sc5 Cell2

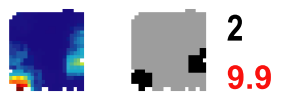

153-04 Sc7 Cell1

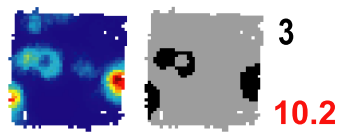

153-04 Sc7 Cell2

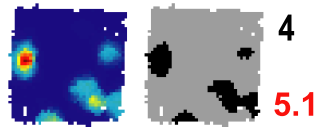

197-14 Sc6 Cell1

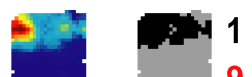

9.1

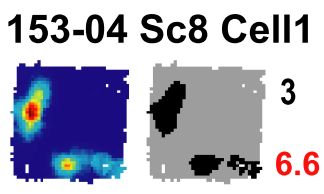

153-04 Sc17 Cell2

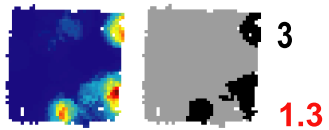

197-14 Sc5 Cell3

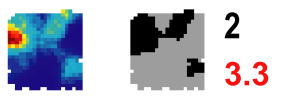

3

Figure 3. $\boldsymbol{A}-\boldsymbol{E}$, Spatial firing rate maps of cells below the granule layer. Rate maps and place-field plots of cells that were localized to the transition between the hilus and zone 3 of Amaral $(\boldsymbol{A}-\boldsymbol{B})$ and to the hilus $(\boldsymbol{C}-\boldsymbol{E})$ based on histological reconstruction of tetrode tracks. For the rate maps, blue represents no firing and red represents peak firing, which is labeled in red to the right of the field plots. In the field plots, black represents the regions that were included in each spatially selective subfield. The number of fields is labeled in black to the right of the field plot. Each region of interest (yellow box; left column) is magnified and shows the tip of the tetrode tracks (arrows; right column). Scale bars: $1 \mathrm{~mm}$ (right) and $50 \mu \mathrm{m}$ (left). All of these examples were recorded on tetrodes that were not adjusted between the time of recordings and the perfusion of the animal.

of cells recorded during behavior). However, the negative relationship suggests that at least two populations of cells contributed to these data, with one population having a higher ratio of active cells during behavior to sleep than the other population. An obvious explanation might be that the two populations were derived from different DG layers. The majority of our tetrodes were localized by postmortem histology to the hilus or to the transition zone between the granule cell layer and hilus (Fig. $1 B, C$ ). We thus began by identifying cells that could be unambiguously excluded from the granule cell layer. Figure 3 shows the histologically identified tetrode tracks and the recordings from the last day of foraging in the open field from five tetrodes of two rats. For rat 153, this session was on the fourth day of recording, and the rat was killed a week later on day 11 . The last adjustment to all tetrodes on this rat was made $5 \mathrm{~d}$ before the recordings shown in Figure 3; thus, the tetrodes had not been moved for $13 \mathrm{~d}$ before the brain perfusion. For rat 197 the last day of foraging in an open field was day 14 , the tetrodes had not been moved in a day (tetrode 5 was retracted $5 \mathrm{~d}$ earlier by $80 \mu \mathrm{m}$ and tetrode 6 was advanced the previous day by $20 \mu \mathrm{m}$ ), and the animal was killed the next day. As indicated in the magnified sections, two of the tetrode tracks ended at the transition between the hilus and zone 3 of Amaral (Amaral, 1978) (Fig. 3A,B), whereas the other three tetrodes were localized to the hilus (Fig. $3 C-E$ ). During sleep, 12 different units fired $<2 \mathrm{~Hz}$ from these five tetrodes. During foraging, eight units showed robust spatial firing based on the previously mentioned criteria. The mean spatial information of these eight units was $1.1 \mathrm{bits} / \mathrm{spike} \pm 0.56 \mathrm{SD}$. The ratio of spatially selective cells to sleep clusters at the five recording sites was slightly variable
$(2 / 5,1 / 1,2 / 2,2 / 3,1 / 1)$, but all showed a relatively high ratio (as in Fig. 1C).

The cells illustrated in Figure 3 fired in multiple locations throughout the enclosure, similar to previously reports from putative granule cells (Jung and McNaughton, 1993; Leutgeb et al., 2007). To quantify the number of fields per cell, a field was defined as 10 contiguous pixels of the rate map, each of which had a firing rate that exceeded $20 \%$ of the peak firing in the rate map. The black place-field maps in Figure 3 show that the majority of the eight spatially selective cells fired in multiple locations (quadruple fields, 1; triple fields, 3; double fields, 3; single fields, 1). Note that even the cell classified as having a single field showed 2-3 peaks in the color-coded rate map. The four nonspatially selective cells showed a variety of firing patterns (data not shown). One cell was silent, two fired diffusely with no clear spatial selectivity (mean rates 0.07 and $5.98 \mathrm{~Hz}$ ), and one appeared to fire in multiple fields, but it did not reach criteria to be considered a spatially selective cell. In contrast to these recording sites localized below the granule layer, of the 26 tetrodes localized histologically to the granule layer (13 tetrodes) or to the transition between the granule cell layer and hilus ( 13 tetrodes), only 1 tetrode recorded a cell with multiple place fields, 5 tetrodes recorded cells with single fields, 13 tetrodes did not record any cells that were active during behavior (although cells were active on these tetrodes during sleep), and 7 tetrodes did not record any cells in either sleep or behavior (perhaps due to poor electrode quality).

Figure $4 A$ shows examples of cells that showed single place fields, similar to the fields typically seen in the CA1 and CA3 
A

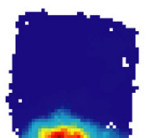

$\begin{array}{ll}1.8 & 10.0\end{array}$
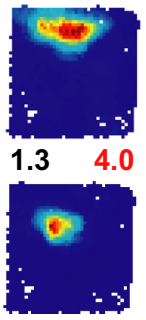

$2.2 \quad 7.9$

B
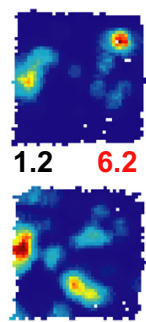

$0.8 \quad 8.6$

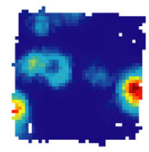

1.010 .2
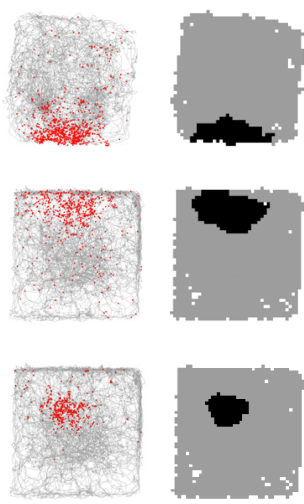

C
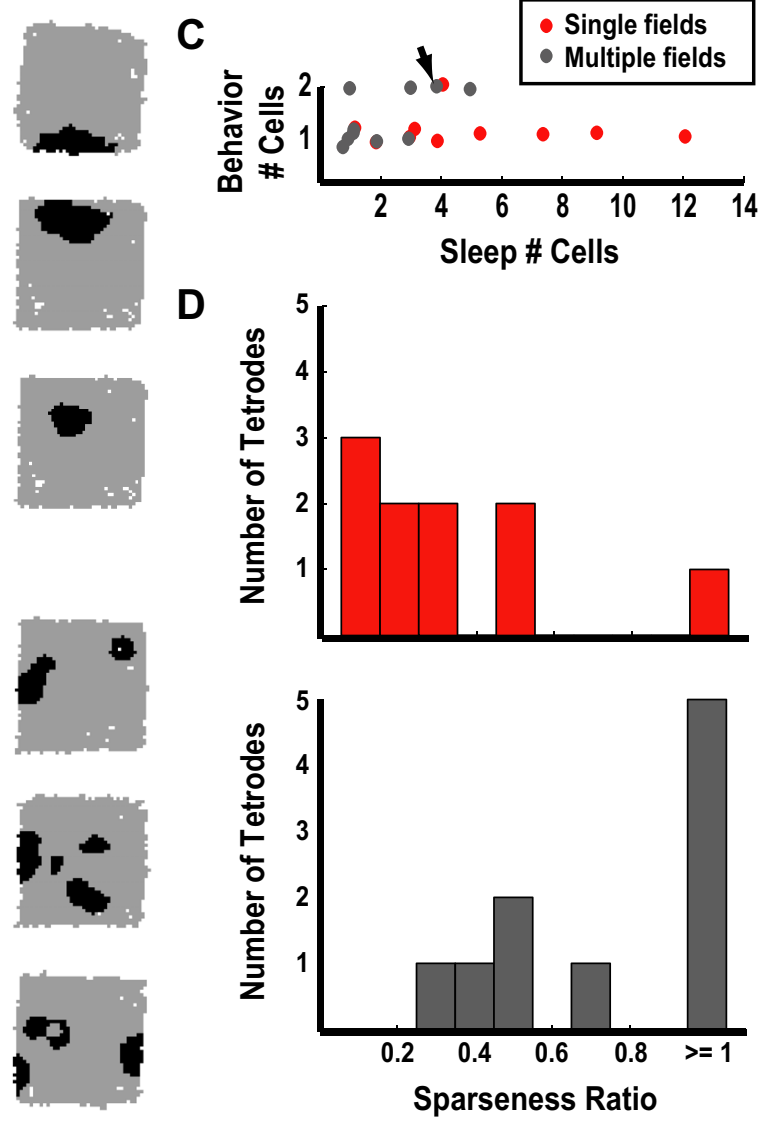

Figure 4. Dissociation of cell types. $\boldsymbol{A}, \boldsymbol{B}$, Examples of cells with single $(\boldsymbol{A})$ and multiple $(\boldsymbol{B})$ fields. Rate maps, plots showing spikes (red) from the cell superimposed on the rat's trajectory (gray), and plots showing all fields are shown in the first, second, and third columns, respectively. For the rate maps, the peak firing rates $(\mathrm{Hz})$ and spatial information scores (bits/spike) were labeled below the lower right and left corners, respectively. $C$, Scatter plot showing the number of active cells during behavior versus the number of cells detected during sleep. Each point represents data from one tetrode (red represents tetrodes detecting cells with only single fields, whereas gray represents tetrodes detecting a cell with multiple fields). The arrow indicates the one ambiguous tetrode that detected a cell with multiple fields and a cell with a single field. Tetrodes recording cells with only single fields had significantly more sleep clusters than tetrodes recording at least one cell with multiple fields $(p<0.05)$. To aid in visualization of overlapping points, jitter was added to the points. $\boldsymbol{D}$, Histograms of sparseness ratios (number of active cells/number of sleep clusters) for tetrodes recording cells with only single fields (top, red bars) and tetrodes recording at least one cell with multiple fields (bottom, gray bars).

regions of the hippocampus. We could not unambiguously identify many of our recordings sites, some of which were located at the transition between the granule cell layer and hilus. For other sites, because the histology was performed many days after the open-field recordings were performed, it was possible that the electrodes may have drifted from the granule layer to the hilus (or to the transition between the granule cell layer and hilus) over that time. Analysis of the number of clusters recorded over days suggested that such a drift occurred, as a number of tetrodes recorded many clusters during sleep in early days (suggesting tetrode placement in a celldense layer), and the number of clusters declined over the course of the next week, despite the very slow approach we took to reach the granule layer. As will be argued below, even if the tetrodes could be localized to the granule layer, it would still be ambiguous whether any particular unit was a mature granule cell, a newborn granule cell, or a cell of the hilus. We thus decided to segregate all of our recording sites based on whether the cells fired in single fields (Fig. 4A) or multiple fields (Fig. $4 B$ ) to determine whether there was evidence that cells with these field properties formed a single class of cells or whether they formed functionally distinct classes of neurons. For all analyses, to exclude repeated samples of cells from the same tetrodes over days, we included recordings from a particular tetrode with active cells only on the day that the most sleep clusters were detected from that tetrode (see Materials and Methods). From this sample, there were 25 spatially active cells during behavior, about half of which fired in multiple locations and half of which fired in single fields (pentuple or more fields, 5; quadruple fields, 2 ; triple fields, 3 ; double fields, 3; single fields, 12).

We first asked whether cells with single fields tended to come from tetrodes with a greater number of active clusters during sleep than did cells with multiple fields. Figure $4 C$ plots, for each tetrode with at least one active, spatially selective cell during behavior, the number of cells recorded on that tetrode during sleep versus the number of cells with spatial firing during behavior. Cells with single fields (red dots) tended to be members of a larger set of simultaneously recorded cells during sleep than cells with multiple fields (gray dots) [i.e., the number of sleep cells per tetrode was higher for single-field than multiple-field cells; single fields: median 4, interquartile range (IQR) 3-7; multiple fields: median 1.5, IQR 1-3; Mann-Whitney $U$ test, $z=2.16, p=0.03$ ]. To quantify the difference in activity between sleep and behavior, we calculated a sparseness index (the number of putative excitatory cells active during behavior divided by the number of putative excitatory cells active during sleep) for each tetrode. [Note that this definition of population sparsity is different from the sparsity measure of individual cell spatial firing that is often used in the literature (Skaggs et al., 1996).] Figure $4 D$ shows that tetrodes recording a cell with only a single field had a significantly lower sparseness index than tetrodes recording cells with multiple fields (single fields: median 0.29, IQR $0.14-0.5$; multiple fields: median 0.83, IQR 0.5-1; Mann-Whitney $U$ test, $z=-2.70, p=0.01$ ). To ensure that the rate maps were not contaminated by spikes that occurred when the rat was immobile and in the LIA state, the data were filtered to remove spikes when the rat moved with low velocity $(<2 \mathrm{~cm} / \mathrm{s})$ and re-analyzed. Identical to the data that were not filtered with respect to velocity, tetrodes recording a cell with only a single field had a significantly lower sparseness index than tetrodes recording cells with multiple fields ( single fields: median 0.29 , IQR 0.14-0.5; multiple fields: median 0.83, IQR 0.5-1; Mann-Whitney $U$ test, $z=-2.70, p<0.01)$. One tetrode simultaneously detected one cell with a single field and one cell with multiple fields, and this tetrode was originally included in the "multiple fields" category. When this tetrode was excluded from the analysis, the results still showed that cells with single fields had a significantly smaller sparseness ratio and had significantly more sleep clusters than cells with multiple fields (data not shown). 
The firing characteristics of active cells were further classified by comparing the size of each field. The area of individual fields was larger for cells with single fields than cells with multiple fields (Fig. 5A; single fields: median $42.1 \mathrm{~cm}^{2}$, IQR $29.0-$ 72.8; multiple fields: median $13.3 \mathrm{~cm}^{2}$, IQR 7.1-21.0; Mann-Whitney $U$ test, $z=$ $4.65, p<0.001)$. However, there was no significant difference between the two groups when looking at the total area of the environment in which each cell was active (Fig. 5B; single fields: median 42.1 $\mathrm{cm}^{2}$, IQR 29.0-72.8; multiple fields: median 53.2 $\mathrm{cm}^{2}$, IQR 36.7-69.3; MannWhitney $U$ test, $z=-0.66, p=0.51$ ). There were no differences between the groups in the mean in-field firing rates (Fig. 5C; single fields: median $2.94 \mathrm{~Hz}$, IQR 1.83-6.06; multiple fields: median 3.77 Hz, IQR 3.01-4.72; Mann-Whitney $U$ test, $z=-0.41, p=0.68)$ and in the peak firing rates (Fig. $5 D$; single fields: median 6.0 Hz, IQR 3.45-13.0; multiple fields: median $11.2 \mathrm{~Hz}$, IQR 8.87-15.3; Mann-Whitney $U$ test, $z=-1.01, p=$ $0.31)$. There was a trend for the spatial information scores of cells recorded on tetrodes with single fields to be higher than those of cells recorded on tetrodes detecting units with multiple fields (Fig. 5E; single median 1.50 bits/spike, IQR 0.951.93; multiple median 1.12 bits/spike, IQR 0.74-1.40; Mann-Whitney $U$ test, $z=1.95, p=0.051)$. To help validate these results, we also performed these analyses on data obtained only from the first day that active cells were recorded during behavior on a given tetrode (rather than on the day with the maximum number of cells). The results were the same (Table 1).

Cell types in the DG have been distinguished by their propensity to fire in bursts in vitro (Scharfman, 1992). Therefore, we examined whether there were differences in the burstiness of active cells during behavior on tetrodes that recorded units with single or multiple fields. Using the criterion of Harris et al. (2001) to measure burstiness, the burst index was defined as the number of times two consecutive spikes occurred within $6 \mathrm{~ms}$ during a cell's spike train divided by the total number of interspike intervals (ISI). Figure $5 F$ shows that cells on tetrodes recording at least one unit with multiple fields were significantly more bursty than cells on tetrodes recording units with only single fields (single fields: median 0.12, IQR 0.050.13 ; multiple fields: median 0.15, IQR 0.12-0.16; Mann-Whitney $U$ test, $z=-2.00, p=0.046$ ). Harris et al. (2001) extended the duration of the ISIs up to $15 \mathrm{~ms}$; therefore, we looked at an extended range of times (i.e., 9, 12, and $15 \mathrm{~ms}$ ) and only detected statistical trends for 9 and $12 \mathrm{~ms}$ (Table 1; Mann-Whitney $U$ test, all $z<-1.8$, all $p<0.07$ ) and no difference for the $15 \mathrm{~ms}$ time span (Table 1; Mann-Whitney $U$ test, $z=-1.51, p=0.13$ ), which was possibly due to the small sample size. No differences in the results were detected when we used the data from only the first day that active cells were recorded to exclude repeated samples compared with the day with the most sleep clusters.
We next examined the firing properties of cells recorded during sleep for those tetrodes that had at least one active cell during behavior. The $6 \mathrm{~ms}$ burst index for cells on tetrodes with single fields was substantially lower than cells on tetrodes with multiple fields (Fig. 6C; single fields: median 0.04, IQR 0.02-0.11; multiple fields: median 0.14, IQR 0.11-0.20; Mann-Whitney $U$ test, $z=3.33, p<0.001)$. Unlike the analyses of data during behavior, there were also significant differences between the two groups using ISI durations of 9, 12, and $15 \mathrm{~ms}$ (Table 1; Mann-Whitney $U$ test, all $z>3.13$, all $p<0.003$ ). The median firing rate during sleep for the cells on tetrodes recording units with single fields was $0.05 \mathrm{~Hz}$ with an IQR of $0.02-0.19$, in contrast to $0.36 \mathrm{~Hz}$ with an IQR of $0.08-0.61$ for cells detected on tetrodes with units that had multiple fields (Fig. 6D; Mann-Whitney $U$ test, $z=3.18, p=0.001$ ), showing that cells recorded on single-field tetrodes fire more sparsely during sleep than cells recorded on multiple-field tetrodes.

The shapes and relative sizes of waveforms recorded on a tetrode can vary based on cell type and cell density of a brain region. For example, the tetrode waveforms recorded from a densely packed layer of small cells might be different from those recorded from a loosely packed layer with large cells. We thus investigated whether cells with single place fields and cells with multiple place fields could be distinguished based on waveform characteristics. The average waveforms across the four wires during sleep from 
Table 1. Results of statistical tests of supplementary analyses

\begin{tabular}{|c|c|c|c|c|c|}
\hline \multirow[b]{2}{*}{ Comparison } & \multirow[b]{2}{*}{$p$ value } & \multicolumn{2}{|c|}{ Single field } & \multicolumn{2}{|c|}{ Multiple fields } \\
\hline & & \multicolumn{2}{|c|}{ Median IQR* } & \multicolumn{2}{|c|}{ Median IQR } \\
\hline \multicolumn{6}{|c|}{ Datasets taken from the day with the most recorded cells on each tetrode } \\
\hline \multicolumn{6}{|l|}{ Behavior } \\
\hline Burst 9 (ms) & 0.052 & 0.17 & $0.10-0.21$ & 0.23 & $0.20-0.24$ \\
\hline Burst 12 (ms) & 0.067 & 0.22 & $0.14-0.28$ & 0.28 & $0.24-0.31$ \\
\hline Burst 15( & 0.13 & 0.25 & $0.18-0.33$ & 0.33 & $0.28-0.36$ \\
\hline \multicolumn{6}{|l|}{ Sleep } \\
\hline Burst 9 (ms) & $8.8 \times 10^{-04}$ & 0.11 & $0.06-0.15$ & 0.20 & $0.17-0.27$ \\
\hline Burst 12 (ms) & $1.7 \times 10^{-03}$ & 0.13 & $0.07-0.22$ & 0.24 & $0.20-0.32$ \\
\hline Burst 15 ( & $1.6 \times 10^{-03}$ & 0.14 & $0.09-0.25$ & 0.26 & $0.23-0.36$ \\
\hline Channel slope & 0.021 & 0.20 & $0.17-0.23$ & 0.17 & $0.13-0.20$ \\
\hline \multicolumn{6}{|c|}{ Datasets taken from the first day that cells were recorded on a tetrode } \\
\hline \multicolumn{6}{|l|}{ Behavior } \\
\hline Subfield area $\left(\mathrm{cm}^{2}\right)$ & \multicolumn{2}{|c|}{$2.4 \times 10^{-05} 42.07$} & \multicolumn{2}{|c|}{$31.11-66.5715 .11$} & $8.00-22.00$ \\
\hline Mean in-field firing rate $(\mathrm{Hz})$ & 0.91 & 3.62 & $1.79-6.06$ & 3.74 & $3.00-4.58$ \\
\hline Burst 6 (ms) & 0.12 & 0.10 & $0.05-0.13$ & 0.15 & $0.12-0.17$ \\
\hline Burst 9 (ms) & 0.08 & 0.15 & $0.10-0.20$ & 0.23 & $0.18-0.26$ \\
\hline Burst 12 (ms) & 0.08 & 0.21 & $0.14-0.27$ & 0.28 & $0.23-0.31$ \\
\hline Burst 15 (ms) & 0.10 & 0.25 & $0.18-0.33$ & 0.33 & $0.27-0.36$ \\
\hline $\begin{array}{l}\text { Spatial information } \\
\text { (bits/spike) }\end{array}$ & 0.13 & 1.50 & $0.93-1.88$ & 1.13 & $0.74-1.60$ \\
\hline Peak firing rate (H & 0.46 & 7.90 & $3.40-12.99$ & 11.22 & $6.67-14.37$ \\
\hline Total field area $\left(\mathrm{cm}^{2}\right)$ & 0.22 & 42.07 & $31.11-66.57$ & 53.78 & $37.33-74.67$ \\
\hline Sparseness ratio & 0.01 & 0.33 & $0.22-0.63$ & 1.00 & $0.75-1.00$ \\
\hline Sleep clust & 0.01 & 3.00 & $2.0-4.47$ & 1.00 & $1.00-2.50$ \\
\hline \multicolumn{6}{|l|}{ Sleep } \\
\hline Duration (ms) & 0.046 & 0.22 & $0.22-0.28$ & 0.28 & $0.25-0.31$ \\
\hline Mean firing rate $(\mathrm{Hz})$ & $7.3 \times 10^{-04}$ & 0.07 & $0.02-0.21$ & 0.43 & $0.17-0.73$ \\
\hline Voltage (mV) & 0.48 & 0.35 & $0.24-0.44$ & 0.29 & $0.22-0.37$ \\
\hline Burst 6 (ms) & $1.1 \times 10^{-06}$ & 0.04 & $0.02-0.09$ & 0.16 & $0.13-0.21$ \\
\hline Burst 9 (ms) & $3.5 \times 10^{-07}$ & 0.08 & $0.05-0.14$ & 0.22 & $0.19-0.28$ \\
\hline Burst 12 (ms) & $2.6 \times 10^{-07}$ & 0.11 & $0.07-0.18$ & 0.26 & $0.23-0.32$ \\
\hline Burst 15 (ms) & $2.3 \times 10^{-07}$ & 0.13 & $0.09-0.21$ & 0.31 & $0.26-0.37$ \\
\hline Normalized amp dif & $1.7 \times 10^{-03}$ & 0.48 & $0.35-0.60$ & 0.32 & $0.22-0.37$ \\
\hline Channel slope & $9.4 \times 10^{-04}$ & 0.21 & $0.18-0.24$ & 0.17 & $0.11-0.18$ \\
\hline
\end{tabular}

$p$ values calculated using Mann-Whitney U-test. *Interquartile range, IQR.

two cells recorded on a tetrode that detected a cell with a single field and a tetrode that recorded a cell with multiple fields are shown in Figure $6 A$ and $B$, respectively. The amplitude of the waveforms in Figure $6 A$ was larger on the third channel than the remaining three channels, whereas the amplitudes of the waveforms in Figure $6 B$ were comparably sized across all channels of the tetrode. We calculated a normalized difference in amplitude index by subtracting the peak amplitude of the smallest waveform of the tetrode from the peak amplitude of the largest waveform and then dividing by the sum. Values closer to zero represent a cell with a waveform that was recorded with similar amplitudes across all four wires, whereas values closer to one represent a cell that had large differences in the peak amplitudes across the tetrode wires. Although much variability and overlap between populations is expected with such a measure, which may depend on the precise location of the tetrode relative to the cell soma, cells with single fields had on average more variation in spike height among the wires of a tetrode than cells with multiple fields (Fig. $6 E$; single fields: median 0.45 , IQR $0.31-0.58$; multiple fields: median 0.34, IQR 0.24-0.41; Mann-Whitney $U$ test; $z=-2.44$, $p=0.01)$. We performed a complementary analysis by sorting all normalized channels of the tetrode (dividing each by the amplitude of the largest channel) in ascending order and calculating the slope of the best-fit line through the four peaks. The mean slope of the cells with single fields was significantly steeper than the mean slope of the cells with multiple fields (single fields: median 0.20, IQR 0.17-0.23; multiple fields: median 0.17, IQR $0.13-$
0.20; Mann-Whitney $U$ test; $z=-2.32, p=0.02$ ), which corroborated the difference seen with the normalized difference in amplitude index.

The shape of individual waveforms might also be a discriminator of cell types, and action potential duration is a common measure to characterize waveform shape. We examined the features of the extracellular waveform recorded during sleep for both groups (Fig. $6 A, B)$ in an attempt to further dissociate the cells recorded on a tetrode classified as either single or multiple fields. The time between the peak of the action potential and the valley occurring after the peak was measured on the mean waveform with the largest amplitude for each cell (Fig. 6A; points b and $\mathrm{c}$ on the red waveform). Figure $6 F$ shows a trend for cells on tetrodes classified as single fields to have action potential durations that are shorter than those seen for cells on tetrodes classified as multiple fields (single fields: median $0.23 \mathrm{~ms}$, IQR $0.22-0.28$; multiple fields: median 0.27 ms, IQR 0.25-0.31; Mann-Whitney $U$ test; $z=1.83, p=$ 0.07 ). In addition, we also compared the maximum voltage (Fig. $6 A$; points $\mathrm{a}$ and $\mathrm{b}$ on the red waveform) of the mean waveform between the two groups. There was a trend for the voltages of cells recorded on tetrodes detecting cells with single fields to be larger than the voltages of cells recorded on tetrodes detecting cells with multiple fields (Fig. 6G; single fields: median $0.38 \mathrm{mV}$, IQR $0.29-$ 0.48; multiple fields: median $0.28 \mathrm{mV}$, IQR 0.22-0.41; MannWhitney $U$ test; $z=-1.84, p=0.07$ ).

\section{Discussion}

The present study examined the spatial firing properties of cells recorded from the DG of the rat hippocampus. Low-rate cells localized below the granule layer showed spatial firing patterns composed of multiple, irregularly arranged subfields (Fig. 3). To our knowledge, the recordings localized to the hilus (Fig. 3C-E) represent the first specific demonstration of spatial firing of cells in the hilus of the DG, a layer that holds a strategic location as the conduit of the only excitatory feedback pathway within the classic trisynaptic loop (Scharfman, 1994, 2007). The only excitatory cell in the hilus is the mossy cell, which receives input from granule cells and feedback from CA3c pyramidal cells. In slices, mossy cells can be distinguished from hilar pyramidal-shaped interneurons (basket cells) based on the lack of burstiness (Scharfman, 1995) and higher firing rate (Lübke et al., 1998) in the latter class of cells. Mossy cells have large cell bodies with large primary dendrites (Amaral, 1978; Ribak et al., 1985; Scharfman and Schwartzkroin, 1988; Scharfman, 1992; Henze and Buzsáki, 2007). Henze and Buszáki (2007) have shown that the spikes of a mossy cell can be recorded from electrodes separated by at least $300 \mu \mathrm{m}$. The low mean firing rates and burstiness of the cells with multiple place fields (as in Fig. 3), coupled with the large size of mossy cells and the large spread of current generated by the spikes of these cells, are consistent with the hypothesis that these cells correspond to mossy cells rather than fast-spiking, inhibitory neurons of the hilus, but this hypothesis requires further testing.

Other neurons recorded from the DG fired in single- and multiple-location patterns, but it was difficult to assign these recording sites unambiguously to a particular layer of the DG using standard histological localization procedures. Published examples of recording sites from DG are also hard to interpret, as the tetrode tips were typically localized at or near the interface between the granule layer and hilus (Jung and McNaughton, 1993; Leutgeb et al., 2007), similar to the tetrode location shown in Figure $1 \mathrm{~B}$. Moreover, because mossy cells can be recorded over such large distances (Henze and Buzsáki, 2007) and because newborn granule cells are initially localized near this interface (Kem- 
permann et al., 2003), it is conceivable that mossy cells, mature granule cells, and newborn granule cells can all be recorded from a tetrode localized to the granule layer. Thus, instead of relying on histology that is hard to interpret, we compared a number of physiological properties between cells that fired in single or multiple locations in an attempt to classify cell types. Cells that fired in single locations during behavior tended to come from tetrodes that recorded high numbers of cells during sleep (Fig. 4C), with a low probability that a cell recorded during sleep would be active during behavior (Fig. $4 D)$. This result is consistent with singlefield cells being localized to the densely packed granule layer, with only a small percentage of cells active in a given environment (Jung and McNaughton, 1993; Skaggs et al., 1996; Chawla et al., 2005). Single-field cells tended to fire at lower rates than multiple-field cells during sleep (Fig. 6D) and were less likely to fire in bursts than multiple-field cells (Figs. 5F, 6C). The resting membrane potential of granule cells is extremely hyperpolarized (Lambert and Jones, 1990; Spruston and Johnston, 1992; Staley et al., 1992; Ylinen et al., 1995; Penttonen et al., 1997), which predicts that granule cells would be difficult to excite. When granule cells are excited, they tend to fire in trains instead of bursts (Scharfman, 1992, 1995; Williamson et al., 1993) and eventually stop spiking in response to excitatory stimuli (Scharfman, 1992; Williamson et al., 1993; Scharfman et al., 2000). These electrophysiological results from identified granule cells in vitro and in anesthetized in vivo preparations are consistent with single-field cells being granule cells. Based on the weight of the evidence, we conclude that most mature granule cells are likely to fire in single locations in a standard recording environment, similar to place cells of CA3 and CA1.

From a computational standpoint, whether a cell fires in only one or multiple locations in an environment is not the major theoretical issue. Rather, the major issues are the sparsity of firing of the cells and the types of remapping they display. Based partly on early reports that granule cells tend to be very silent and difficult to drive (O'Keefe and Nadel, 1978), classic computational theories suggested that granule cells form a very sparse representation and that they perform a pattern separation function by forming independent codes for different environments or locations (McNaughton and Nadel, 1990; Rolls and Treves, 1998). These notions were questioned by Leutgeb et al. (2007), who emphasized that putative granule cells (with primarily multipeaked firing fields) fired rather promiscuously in multiple environments and used a rate-remapping code to distinguish environments. The present data show that this important question is not yet settled, as it is very likely that the majority of cells recorded from the densely packed granule layer have a very low probability of firing in a given environ-
B $\square$ Multiple
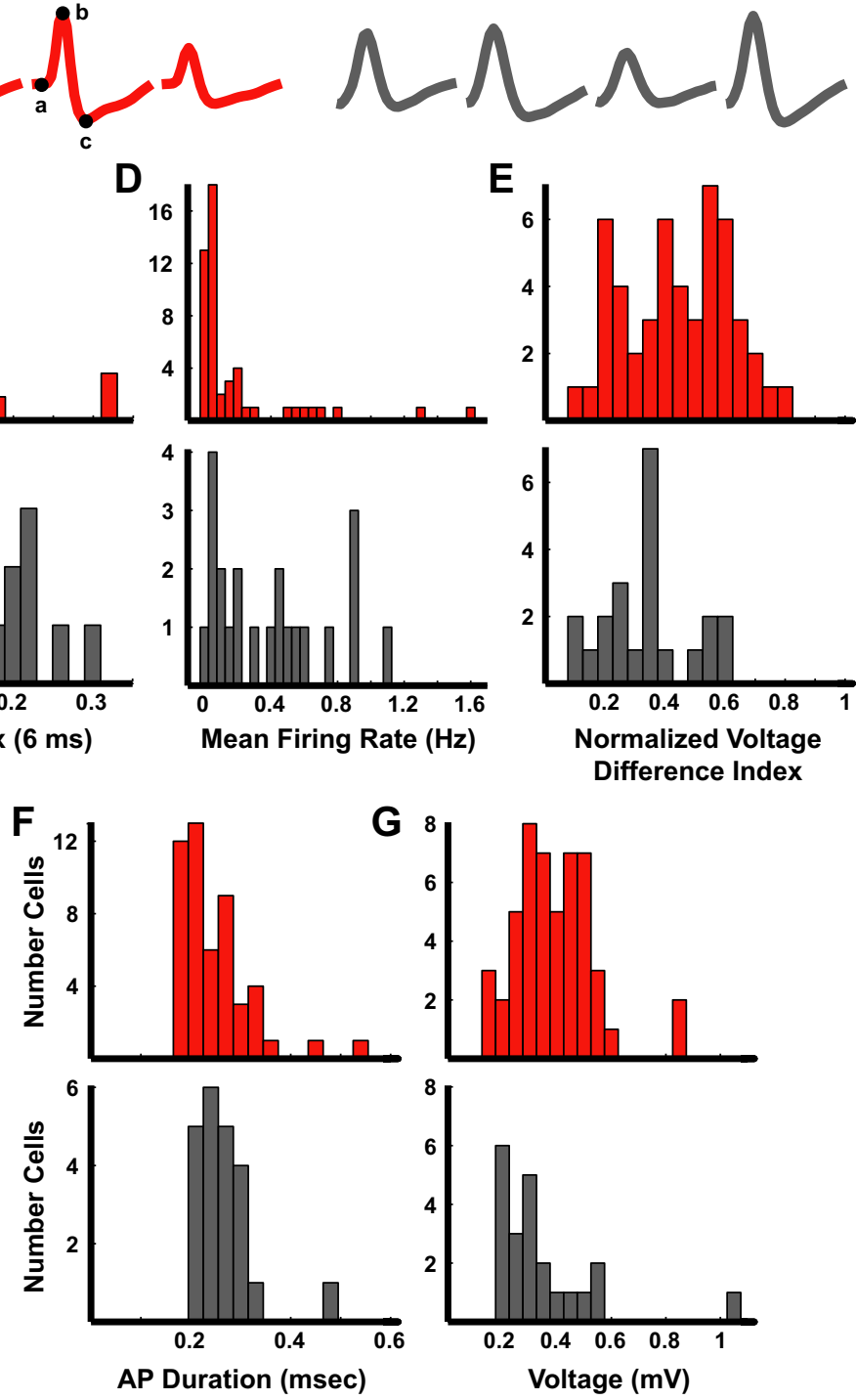

Figure 6. Firing characteristics of cells during sleep. $\boldsymbol{A}, \boldsymbol{B}$, Examples of the mean waveforms recorded during sleep on four determine voltage (height of $a$ to $b$ ) and duration (time between $b$ and $c$ ) of the action potential. $\mathbf{C}-\mathbf{G}$, Histograms of the burst index $(\boldsymbol{C})$ for each cell in the two groups, the mean firing rate $(\boldsymbol{D})$, the normalized voltage difference between the channels with the largest and smallest amplitudes on the tetrode $(\boldsymbol{E})$, the action potential duration $(\boldsymbol{F})$, and the maximum voltage $(\boldsymbol{G})$.

ment. We did not perform remapping experiments on an open field in this study, and thus we cannot address whether these sparse-encoding, single-field cells perform a global remapping (as predicted by classical theories) or a rate remapping. This is an important question for future experiments.

It is important to note that the spatial firing patterns reported here do not differ markedly from the data presented by Jung and McNaughton (1993) and by Leutgeb et al. (2007). Both previous studies reported single- and multiple-field cells and acknowledged that a fraction of the cells might have come from the hilus. Like our observations, Jung and McNaughton (1993) also reported anecdotally that it was often necessary to wait until the animal fell asleep in a baseline session to determine whether recordable granule cells were present, as the cells were mostly silent when the animal was alert. In contrast, Leutgeb et al. (2007) reported a small number of DG cells that fired only in sleep (similar to the multifield results of the present study). Both of 
those studies assumed that their recordings originated primarily from mature granule cells, which far outnumber any other cell type in the DG. However, if the overwhelming majority of mature granule cells are silent (Fig. 2C, 4D), and other cell types are more likely to be active, this argument becomes tenuous, and the previous papers did not attempt to dissociate cells that fired in single fields from cells that fired in multiple fields. Thus, the present demonstration that single- and multiple-field cells constitute distinct cell types advances our understanding of the variety of firing patterns of DG neurons and raises the questions of what cell type corresponds to mature granule cells versus the multiplicity of other cell types in the DG.

Alme et al. (2010) suggested that almost all active cells during behavior are newborn granule cells, with older cells virtually silent. Newborn granule cells are more excitable than older granule cells and are more likely to undergo long-term potentiation (Wang et al., 2000; Schmidt-Hieber et al., 2004; Ge et al., 2006). Both of these properties are likely to make newborn cells more active than older cells. It is possible that mature granule cells fire in single fields, whereas newborn granule cells fire in multiple fields and fire more promiscuously across environments. An unambiguous answer to the question of whether there are differences in the spatial correlates among these cell types might require the use of juxtacellular or genetic labeling techniques to positively identify them and then test their spatial correlates. In the absence of these techniques, it is essential that one record for long periods of sleep/rest to determine whether the electrode is in the middle of a dense layer of very sparsely firing cells or in a layer of less densely packed, more active cells to estimate whether the recordings are likely from the granule cell layer or hilus. Otherwise, it is very easy to move the electrodes right through the granule layer without realizing it, given the extremely sparse firing rates of most of these cells during wakefulness (Jung and McNaughton, 1993; Williamson et al., 1993; Skaggs et al., 1996).

Based on the report by Leutgeb et al. (2007), recent computational studies have attempted to model the transformation of medial entorhinal cortex (MEC) grid cells to the irregular, multipunctate firing of DG granule cells (de Almeida et al., 2009; Si and Treves, 2009; Ujfalussy et al., 2009). The present results suggest that the transformation from MEC firing to mature granule cell firing is really one from a grid-cell representation to a very sparse representation of mainly single-location place fields (Solstad et al., 2006; Savelli and Knierim, 2010). As such, our results support long-standing notions of the DG as a sparse encoding system, which is supported strongly by the Arc expression results (Chawla et al., 2005). The challenge for future work is to further disentangle the behavioral correlates of physiologically and/or morphologically characterized cells of the DG to allow for more thorough tests to determine the roles of each cell type in the DG circuit.

\section{References}

Acsády L, Kamondi A, Sík A, Freund T, Buzsáki G (1998) GABAergic cells are the major postsynaptic targets of mossy fibers in the rat hippocampus. J Neurosci 18:3386-3403.

Alme CB, Buzzetti RA, Marrone DF, Leutgeb JK, Chawla MK, Schaner MJ, Bohanick JD, Khoboko T, Leutgeb S, Moser EI, Moser MB, McNaughton BL, Barnes CA (2010) Hippocampal granule cells opt for early retirement. Hippocampus 20:1109-1123.

Altman J, Das GD (1965) Autoradiographic and histological evidence of postnatal hippocampal neurogenesis in rats. J Comp Neurol 124:319-335.

Amaral DG (1978) A Golgi study of cell types in the hilar region of the hippocampus in the rat. J Comp Neurol 182:851-914.

Amaral DG, Witter MP (1989) The three-dimensional organization of the hippocampal formation: a review of anatomical data. Neuroscience 31:571-591.

Bragin A, Jandó G, Nádasdy Z, Hetke J, Wise K, Buzsáki G (1995a) Gamma $(40-100 \mathrm{~Hz})$ oscillation in the hippocampus of the behaving rat. J Neurosci 15:47-60.

Bragin A, Jandó G, Nádasdy Z, van LM, Buzsáki G (1995b) Dentate EEG spikes and associated interneuronal population bursts in the hippocampal hilar region of the rat. J Neurophysiol 73:1691-1705.

Chawla MK, Guzowski JF, Ramirez-Amaya V, Lipa P, Hoffman KL, Marriott LK, Worley PF, McNaughton BL, Barnes CA (2005) Sparse, environmentally selective expression of Arc RNA in the upper blade of the rodent fascia dentata by brief spatial experience. Hippocampus 15:579-586.

de Almeida L, Idiart M, Lisman JE (2009) The input-output transformation of the hippocampal granule cells: from grid cells to place fields. J Neurosci 29:7504-7512.

Ge S, Goh EL, Sailor KA, Kitabatake Y, Ming GL, Song H (2006) GABA regulates synaptic integration of newly generated neurons in the adult brain. Nature 439:589-593.

Gothard KM, Hoffman KL, Battaglia FP, McNaughton BL (2001) Dentate gyrus and CA1 ensemble activity during spatial reference frame shifts in the presence and absence of visual input. J Neurosci 21:7284-7292.

Harris KD, Hirase H, Leinekugel X, Henze DA, Buzsáki G (2001) Temporal interaction between single spikes and complex spike bursts in hippocampal pyramidal cells. Neuron 32:141-149.

Henze DA, Buzsáki G (2007) Hilar mossy cells: functional identification and activity in vivo. Prog Brain Res 163:199-216.

Hunsaker MR, Kesner RP (2008) Evaluating the differential roles of the dorsal dentate gyrus, dorsal CA3, and dorsal CA1 during a temporal ordering for spatial locations task. Hippocampus 18:955-964.

Hunsaker MR, Rosenberg JS, Kesner RP (2008) The role of the dentate gyrus, CA3a,b, and CA3c for detecting spatial and environmental novelty. Hippocampus 18:1064-1073.

Jung MW, McNaughton BL (1993) Spatial selectivity of unit activity in the hippocampal granular layer. Hippocampus 3:165-182.

Kaplan MS, Hinds JW (1977) Neurogenesis in the adult rat: electron microscopic analysis of light radioautographs. Science 197:1092-1094.

Kempermann G, Gast D, Kronenberg G, Yamaguchi M, Gage FH (2003) Early determination and long-term persistence of adult-generated new neurons in the hippocampus of mice. Development 130:391-399.

Kuhn HG, Dickinson-Anson H, Gage FH (1996) Neurogenesis in the dentate gyrus of the adult rat: age-related decrease of neuronal progenitor proliferation. J Neurosci 16:2027-2033.

Lambert JD, Jones RS (1990) A reevaluation of excitatory amino acidmediated synaptic transmission in rat dentate gyrus. J Neurophysiol 64:119-132.

Leutgeb JK, Leutgeb S, Moser MB, Moser EI (2007) Pattern separation in the dentate gyrus and CA3 of the hippocampus. Science 315:961-966.

Lübke J, Frotscher M, Spruston N (1998) Specialized electrophysiological properties of anatomically identified neurons in the hilar region of the rat fascia dentata. J Neurophysiol 79:1518-1534.

McHugh TJ, Jones MW, Quinn JJ, Balthasar N, Coppari R, Elmquist JK, Lowell BB, Fanselow MS, Wilson MA, Tonegawa S (2007) Dentate gyrus NMDA receptors mediate rapid pattern separation in the hippocampal network. Science 317:94-99.

McNaughton BL, Morris RG (1987) Hippocampal synaptic enhancement and information storage within a distributed memory system. Trends Neurosci 10:408-415.

McNaughton BL, Nadel L (1990) Hebb-Marr networks and the neurobiological representation of action in space. In: Neuroscience and connectionist theory. (Gluck MA, Rumelhart DE, eds), pp 1-63. Hillsdale, NJ: Erlbaum.

McNaughton BL, Barnes CA, Meltzer J, Sutherland RJ (1989) Hippocampal granule cells are necessary for normal spatial learning but not for spatially-selective pyramidal cell discharge. Exp Brain Res 76:485-496.

Myers CE, Scharfman HE (2009) A role for hilar cells in pattern separation in the dentate gyrus: a computational approach. Hippocampus 19:321-337.

O'Keefe J (1976) Place units in the hippocampus of the freely moving rat. Exp Neurol 51:78-109.

O'Keefe J, Nadel L (1978) The hippocampus as a cognitive map. Oxford: Clarendon. 
O’Reilly RC, McClelland JL (1994) Hippocampal conjunctive encoding, storage, and recall: avoiding a trade-off. Hippocampus 4:661-682.

Penttonen M, Kamondi A, Sik A, Acsády L, Buzsáki G (1997) Feed-forward and feed-back activation of the dentate gyrus in vivo during dentate spikes and sharp wave bursts. Hippocampus 7:437-450.

Ramon y Cajal S (1995) Histology of the nervous system of man and vertebrates, Vol. II. New York: Oxford UP.

Ribak CE, Seress L, Amaral DG (1985) The development, ultrastructure and synaptic connections of the mossy cells of the dentate gyrus. J Neurocytol 14:835-857.

Rolls ET (2007) An attractor network in the hippocampus: theory and neurophysiology. Learn Mem 14:714-731.

Rolls ET, Kesner RP (2006) A computational theory of hippocampal function, and empirical tests of the theory. Prog Neurobiol 79:1-48.

Rolls ET, Treves A (1998) Neural networks and brain function. Oxford: Oxford UP.

Savelli F, Knierim JJ (2010) Hebbian analysis of the transformation of medial entorhinal grid-cell inputs to hippocampal place fields. J Neurophysiol 103:3167-3183.

Scharfman HE (1992) Differentiation of rat dentate neurons by morphology and electrophysiology in hippocampal slices: granule cells, spiny hilar cells and aspiny 'fast-spiking' cells. Epilepsy Res [Suppl] 7:93-109.

Scharfman HE (1994) Evidence from simultaneous intracellular recordings in rat hippocampal slices that area CA3 pyramidal cells innervate dentate hilar mossy cells. J Neurophysiol 72:2167-2180.

Scharfman HE (1995) Electrophysiological diversity of pyramidal-shaped neurons at the granule cell layer/hilus border of the rat dentate gyrus recorded in vitro. Hippocampus 5:287-305.

Scharfman HE (2007) The CA3 "backprojection" to the dentate gyrus. Prog Brain Res 163:627-637.

Scharfman HE, Schwartzkroin PA (1988) Electrophysiology of morphologically identified mossy cells of the dentate hilus recorded in guinea pig hippocampal slices. J Neurosci 8:3812-3821.

Scharfman HE, Goodman JH, Sollas AL (2000) Granule-like neurons at the hilar/CA3 border after status epilepticus and their synchrony with area CA3 pyramidal cells: functional implications of seizure-induced neurogenesis. J Neurosci 20:6144-6158.

Schmidt-Hieber C, Jonas P, Bischofberger J (2004) Enhanced synaptic plas- ticity in newly generated granule cells of the adult hippocampus. Nature 429:184-187.

Shen J, Kudrimoti HS, McNaughton BL, Barnes CA (1998) Reactivation of neuronal ensembles in hippocampal dentate gyrus during sleep after spatial experience. J Sleep Res 7 [Suppl] 1:6-16.

Si B, Treves A (2009) The role of competitive learning in the generation of DG fields from EC inputs. Cogn Neurodyn 3:177-187.

Skaggs WE, McNaughton BL, Wilson MA, Barnes CA (1996) Theta phase precession in hippocampal neuronal populations and the compression of temporal sequences. Hippocampus 6:149-172.

Solstad T, Moser EI, Einevoll GT (2006) From grid cells to place cells: a mathematical model. Hippocampus 16:1026-1031.

Spruston N, Johnston D (1992) Perforated patch-clamp analysis of the passive membrane properties of three classes of hippocampal neurons. J Neurophysiol 67:508-529.

Staley KJ, Otis TS, Mody I (1992) Membrane properties of dentate gyrus granule cells: comparison of sharp microelectrode and whole-cell recordings. J Neurophysiol 67:1346-1358.

Sutherland RJ, Whishaw IQ, Kolb B (1983) A behavioural analysis of spatial localization following electrolytic, kainate- or colchicine-induced damage to the hippocampal formation in the rat. Behav Brain Res 7:133-153.

Ujfalussy B, Kiss T, Erdi P (2009) Parallel computational subunits in dentate granule cells generate multiple place fields. PLoS Comput Biol 5:e1000500.

Wang S, Scott BW, Wojtowicz JM (2000) Heterogenous properties of dentate granule neurons in the adult rat. J Neurobiol 42:248-257.

Whishaw IQ (1987) Hippocampal, granule cell and CA3-4 lesions impair formation of a place learning-set in the rat and induce reflex epilepsy. Behav Brain Res 24:59-72.

Williamson A, Spencer DD, Shepherd GM (1993) Comparison between the membrane and synaptic properties of human and rodent dentate granule cells. Brain Res 622:194-202.

Xavier GF, Oliveira-Filho FJ, Santos AM (1999) Dentate gyrus-selective colchicine lesion and disruption of performance in spatial tasks: difficulties in "place strategy" because of a lack of flexibility in the use of environmental cues? Hippocampus 9:668-681.

Ylinen A, Soltész I, Bragin A, Penttonen M, Sik A, Buzsáki G (1995) Intracellular correlates of hippocampal theta rhythm in identified pyramidal cells, granule cells, and basket cells. Hippocampus 5:78-90. 